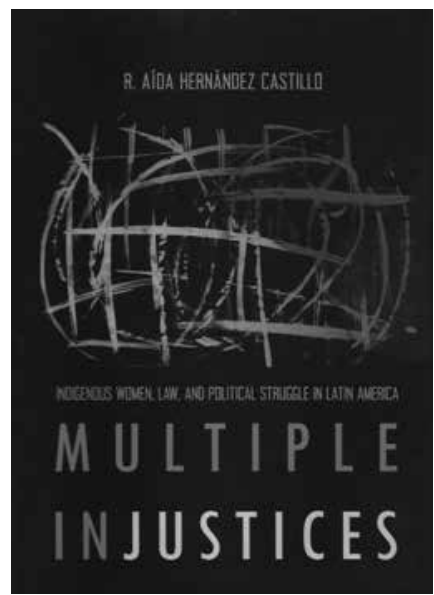

- Multiple Injustices. Indigenous Women,

Law and Political Struggle in Latin

America

Rosalva Aída Hernández Castillo, 2016

University of Arizona Press, Tucson

\title{
Mujeres indígenas creando teoría y acción política
}

\author{
PAMELA CALLA
}

Indigenous Women Creating

Theory and Action in Politics

Pamela Calla

Center for Latin American and Caribbean Studies, New York University, Nueva York, Estados Unidos pc1210@nyu.edu

Desacatos 57 , mayo-agosto 2018, pp. 212-213

ste libro de Rosalva Aída Hernández Castillo es resultado de 25 años de investigación-acción comprometida con mujeres indígenas en diversas regiones de México, Colombia y Guatemala. Multiple Injustices... presenta tres ejes teóricos transversales: la vernacularización del discurso de derechos; los usos hegemónicos y contrahegemónicos de la legalidad por parte del Estado y de mujeres indígenas en contextos de pluralismo legal, y los límites de la resistencia contra estrategias de gobernanza neoliberal y violencia de Estado. El propósito académico-activista de Hernández Castillo es acercarnos, entender y sentir las encrucijadas sistémicas, legales, personales y políticas vividas por estas mujeres, y darnos herramientas para reconocer y recuperar la ecología de conocimientos feministas construidos por ellas, urdidos en complejos y abigarrados procesos de vernacularización histórica y culturalmente específicos.

La transición de un Estado multicultural neoliberal de reconocimientos - limitados y contradictorios - de los derechos indígenas a un Estado penal es central en el análisis de la vernacularización del discurso de derechos porque allí se reconfiguran los regímenes de violencia de género y raciales imperantes. Dada la intensificación de los procesos de acumulación por despojo, acompañada por una 
"semántica de violencia e impunidad patriarcal", la violencia sexual, explica la autora, se articula con la violencia militar y policial estatal y no se usa sólo como estrategia represiva, también garantiza las condiciones para la desacralización del territorio, sus fuentes de agua y de vida, y convierte los cuerpos de las mujeres en "territorios" sacrificables, desechables, que se pueden invadir. En consideración de lo concreto de las migraciones masivas y el manto desvelado del narcotráfico que afecta al continente, éste es de los pocos libros que articula el complejo industrial extractivista — que conlleva nociones hegemónicas de desarrollismo basado en la extracción depredadora del medio ambiente - al complejo industrial carcelario —que se privatiza globalmente y se beneficia de la criminalización de la pobreza y la disidencia- desde una perspectiva de género racializada. El feminicidio, la expulsión del territorio y el encarcelamiento son efectos concretos de la criminalización de mujeres y hombres de los movimientos sociales e indígenas. En estos sitios de lucha y resistencia política nos encontramos con las mujeres indígenas con las que trabaja Hernández Castillo.

Las mujeres ma'phee, nahua, nasa y de otros pueblos, y las organizaciones con las que Aída colabora en proyectos de investigación-acción se vinculan ante este proceso de criminalización y nociones de desechabilidad para encarar de manera frontal las violencias permeadas con la semántica patriarcal y colonial. Hernández Castillo nos lleva por diversas instancias y proyectos, en los que ella y estas mujeres comparten el poder de sus trayectorias de vida y construyen, en su cotidianidad comunal y organizativa, significados, teorías, tácticas y estrategias. El trabajo cubre ámbitos transnacionales, como la Corte Interamericana de Derechos Humanos, en los que la actuación política de las mujeres desestabiliza y complejiza nociones liberales de persona, cuerpo y violencia. Así, la lucha legal en esta Corte, de Inés Fernández Ortega, del pueblo ma'phee, sienta precedente respecto al entendimiento de la violencia sexual no sólo como violación de los derechos reproductivos individuales de las mujeres sino también como violación de los derechos colectivos de autodeterminación y autonomía de mujeres y hombres indígenas. La violación contra un individuo, explica, impacta a toda su comunidad. Considerar el contexto cultural de esta persona como una dimensión crucial en la comprensión de cómo es vivida la violencia de género es central para imaginar la justicia. Hernández Castillo se inserta también en proyectos localizados en el sistema carcelario del estado de Morelos, México, como los Talleres Penitenciarios en el Centro de Readaptación Social, en los que mujeres indígenas y no indígenas dialogan a partir de sus historias orales y empiezan a desarticular sus múltiples opresiones para conectarse entre ellas, alfabetizarse algunas, hasta construir el poder de teorizar e interpretar su propia realidad, y convertirse en autoras de sus historias y las de sus comunidades — comunidad entendida no sólo como rural- Un proyecto de escritura de poesía y testimonios para mujeres en el sistema carcelario fue la base para la formación de la Colectiva Editorial de Hermanas en la Sombra. Hernández Castillo traslada entonces teorizaciones colectivas del ámbito activista al académico para después volver al activismo político. Así logra un riguroso trabajo en el que la investigación colaborativa se hace efectiva y productiva.

Este libro nos servirá a todos los interesados en el género de los complejos industriales extractivistas y carcelarios que dan forma a la estructura del capitalismo y desarrollismo contemporáneos. Servirá también a los interesados en experiencias concretas de intentos de descolonización y despatriarcalización de institucionalidades locales, nacionales y transnacionales. Sobre todo, es central para quienes trabajamos con, y quienes nos reconocemos como, mujeres indígenas para seguir la labor de aflojar la velocidad rapaz del patriarcado capitalista y despatriarcalizar el Estado, la sociedad, la política de los movimientos, incluida la política de los movimientos indígenas. $\mathbb{D}$ 